\title{
PREOPERATIVE EVALUATION OF SEXUAL FUNCTION IN PATIENTS UNDERGOING BILATERAL NERVE-SPARING RADICAL RETROPUBIC PROSTATECTOMY
}

\author{
Boyan A. Stoykov, \\ Nikolay H. Kolev, \\ Rumen P. Kotsev, \\ Fahd Al-Shargabi, \\ Pencho P. Genov', \\ Aleksandar Vanov, \\ Jitian A. Atanasov, \\ Manish Sachdeva, \\ Pencho T. Tonchev ${ }^{2}$, \\ Maria I. Koleva ${ }^{3}$ \\ Department of Urology, \\ Medical University - Pleven, \\ Bulgaria \\ ${ }^{1}$ Department of Urology, \\ UMHAT Ruse, Bulgaria \\ ${ }^{2}$ Department of Surgery, \\ Medical University - Pleven, \\ Bulgaria \\ ${ }^{3}$ Clinic Physiomed, \\ Pleven, Bulgaria
}

\author{
Corresponding Author: \\ Boyan Atanasov \\ Clinic of Urology, \\ University Hospital - Pleven \\ 8a, G. Kochev Blvd. \\ Pleven, 5800 \\ Bulgaria \\ e-mail:atanasovmd@yahoo.com
}

Received: June 15, 2017

Revision received: June 26, 2017

Accepted: November 02, 2017

\section{Summary}

During the last few years, prostate cancer is more frequently diagnosed in young patients. This lays emphasis on the necessity to preoperatively evaluate the sexual function in patients undergoing bilateral nerve sparing radical retropubic prostatectomy (BNSRRP). The aim of our study was to make an objective evaluation of the basic sexual function in patients with clinically localized prostate cancer and candidates for BNSRRP, using internationally validated questionnaires. We also tried to find a correlation between these questionnaires and the individual assessment of candidates, on one hand, and between comorbidities of the patients and degree of erectile dysfunction (ED), on the other hand. From January 2014 to March 2017, at the urology clinic of University Hospital - Pleven, 64 patients opted BNSRRP and reported to have preserved erectile function (EF), wishing to maintain this function after surgery. The patients' histories and comorbidities were recorded on the day of hospitalization. The subjective assessment of the patients' potency was compared with International Index of Erectile Function (IIEF). According to the EF domain of the IIEF, baseline EF was assessed in 28 patients. Twelve patients had mild ED, 9 patients had mild to moderate ED, seven patients had moderate, and eight had severe ED. The results showed that a significant number of patients with clinically localized prostate cancer who were candidates for BNSRRP reported to be fully potent but actually had impaired EF preoperatively. There was also a pronounced correlation between concomitant diseases and EF.

Key words: sexual function, erectile function, erectile dysfunction, bilateral nerve-sparing radical retropubic prostatectomy

\section{Introduction}

Many recent studies have identified prostate cancer as the most common cancer in men [1]. Every year, 100000 cases of prostate malignancies are diagnosed in Europe. This number tends to increase during early screening of the prostate. According to the recommendations of the European Urology Association 2017, bilateral or unilateral nerve-sparing radical prostatectomy remains the first choice in patients with localized prostate cancer, life expectancy over 10 years, and normal preoperative 
sexual function.

Numerous recent randomized clinical trials and meta-analysis have indicated that surgical treatment performed at an early stage of the disease is associated with better survival of patients than in cases with conservative treatment [2] or radiotherapy [3, 4]. Although the surgical approach is associated with excellent long-term oncological results $[5,6]$, the risk of short-term and long-term adverse events is not negligible $[7,8]$. The progress made in our understanding of prostate surgery and improved surgical techniques do not, unfortunately, reduce the percentage of patients with urinary incontinence and erectile dysfunction (ED) after radical prostatectomy (RP). The incidence of postoperative ED varies widely - between $14 \%$ and $90 \%[9,10]$. This is a significant problem for the physician and the patient, since prostate cancer is diagnosed in sexually active young men who wish to maintain the same quality of life after surgery $[11,12]$. Preoperative characteristics of patients are known to play a key role in the recovery of erectile function (EF) after surgery, in which case young and healthy patients have significantly higher rates of recovery than old and diseased patients [13-19].

The aim of this study was to make an objective assessment of the preoperative sexual function of patients with clinically localized prostate cancer, who were candidates for bilateral nerve sparing radical retropubic prostatectomy (BNSRRP). We used internationally validated questionnaires. We aimed to determine whether there was a correlation between these questionnaires and the individual judgment of the candidate, and between the concomitant illnesses of the patients and the degree of EF. Another important goal was to investigate whether there was a correlation between the degree of ED and the degree of other domains of the International Index of Erectile Function (IIEF).

\section{Materials and Methods}

From January 2014 to March 2017, 64 patients, treated at the urology clinic of the university hospital Pleven underwent BNSRRP reported that they had a preserved EF and wished this function to be preserved after surgery. The mean age of the 64 patients was 65.7 years, and all patients agreed to fill in the questionnaires. The inclusion criteria were: stage $\mathrm{T} 1 \mathrm{c}, \mathrm{T} 2 \mathrm{a}$ or $\mathrm{T} 2 \mathrm{~b}$, Gleason score 6 and 7, life expectancy over 10 years and normal preoperative sexual function. The distribution of patients by age, stage and Gleason score is shown in Table 1.

On the day before the surgery, detailed history of the accompanying disease and sexual history was taken for all the patients selected for BNSRRP. To identify existing concomitant illnesses, additional blood glucose level, lipid profile and total testosterone tests were added to standard preoperative evaluation of the patients included in the study. The subjective assessment of patients' potency and erectile strength was compared to IIEF and the erection hardness score (EHS).

Table1. Distribution of patients by age, stage and Gleason score

\begin{tabular}{lllcll}
\hline Age (Years) & Patients & Stage & Patients & Gleason & Patients \\
\hline$>\mathbf{5 4}$ & 6 & T1c & 10 & 6 & 0 \\
$\mathbf{5 5 - 5 9}$ & 11 & T2a & 22 & 7 & 9 \\
$\mathbf{6 0 - 6 4}$ & 20 & T2b & 32 & 7 & 55 \\
$\mathbf{6 5 - 6 9}$ & 28 & T2c & 0 & 7 & 0 \\
\hline
\end{tabular}

\section{Results}

The average number of points according to the five domains of IIEF: EF, orgasm function, sexual desire, satisfaction from the sexual activity and overall patient satisfaction are shown in Table 2. From the table, it can be seen that the preoperative average value of the erectile and orgasmic function domain corresponds to mild dysfunction. The average value of the sexual desire domain shows mild to moderate dysfunction. The satisfaction from the sexual activity was assessed as a moderate, and the overall satisfaction of the act was defined as mild impairment. The total number of points was 46 out of 75 . 
Table 2. Preoperative condition of sexual function according to IIEF

\begin{tabular}{ll}
\hline IIEF $^{*}$ & Average points \\
\hline Erectile function (30 points) & 19.7 \\
\hline Orgasmic function (10 points) & 6.6 \\
\hline Sexual desire (10 points) & 6.3 \\
\hline Satisfaction post act (15 points) & 6.4 \\
\hline Overall satisfaction (10 points) & 6.9 \\
\hline
\end{tabular}

*IIEF - International Index of Erectile Function.

The distribution of patients according to the EF domain and the EHS is shown in Table 3. According to IIEF, only $44 \%$ of the patients had normal EF preoperatively, although all stated that they had a normal EF. Among all the patients who participated in the study, $18.7 \%$ had mild ED, $14.1 \%$ had mild to moderate dysfunction,
$10.9 \%$ had moderate $\mathrm{ED}$, and $12.5 \%$ had severe ED. As per the EHS, it was found that the better the patients' EF was, the higher the number of points was. The maximum number of points -4 , was reported in patients with normal EF, while the minimum number of points was registered in patients with severe ED.

Table 3. Preoperative condition of erectile function according to IIEF and EHS

\begin{tabular}{lll}
\hline Erectile function & Number of patients & Erection hardness score (points) \\
\hline Normal EF* & $28 / 64$ & 4 \\
\hline Mild ED $\dagger$ & $12 / 64$ & 3 \\
\hline Mild to moderate ED & $9 / 64$ & 2 \\
\hline Moderate & $7 / 64$ & 1 \\
\hline Severe ED & $8 / 64$ & 0 \\
\hline
\end{tabular}

$* \mathrm{EF}-$ Erectile function, $† \mathrm{ED}$ - Erectile dysfunction

The distribution of patients by number according to the different domains and the degree of EF is presented in Table 4. From the table it can be seen that patients with normal $\mathrm{EF}$ also had a normal orgasmic function, mildly impaired sexual desire and satisfaction from the act while retaining overall satisfaction from sexual intercourse. Patients with mild ED also had a mildly impaired orgasmic function, mild to moderate impairment of sexual desire and satisfaction from the act with mildly impaired overall satisfaction. The same trend was found in patients with mild to moderate, moderate and severe ED.

Table 4. Distribution of patients according to different domains of IIEF

\begin{tabular}{llllll}
\hline $\begin{array}{l}\text { Erectile } \\
\text { function }\end{array}$ & $\begin{array}{l}\text { Number of } \\
\text { patients }\end{array}$ & $\begin{array}{l}\text { Orgasm } \\
\text { function } \\
(\mathbf{1 0} \text { points })\end{array}$ & $\begin{array}{l}\text { Sexual desire } \\
(\mathbf{1 0} \text { points) }\end{array}$ & $\begin{array}{l}\text { Satisfaction from } \\
\text { the act } \\
(\mathbf{1 5} \text { points })\end{array}$ & $\begin{array}{l}\text { Overall } \\
\text { satisfaction } \\
\text { (10 points) }\end{array}$ \\
\hline Normal EF* & $28 / 64$ & 9.3 & 7.0 & 11.3 & 8.5 \\
\hline Mild ED $\dagger$ & $12 / 64$ & 8.4 & 6.2 & 9.4 & 7.7 \\
\hline $\begin{array}{l}\text { Mild to } \\
\text { moderate ED }\end{array}$ & $9 / 64$ & 7.3 & 6.1 & 9.0 & 6.8 \\
\hline Moderate ED & $7 / 64$ & 7.8 & 5.3 & 5.2 & 4.9 \\
\hline Severe ED & $8 / 64$ & 1.1 & 3.9 & 0.8 & 3.2 \\
\hline
\end{tabular}

*EF - Erectile Function, $† \mathrm{ED}$ - Erectile Dysfunction 
The distribution of patients according to $\mathrm{EF}$ and concomitant diseases is shown in Table 5. The patients with normal EF had no diabetes, and $21 \%$ of them reported concomitant hypertension and $11 \%$ - coronary heart disease. Of the patients with mild ED, $8 \%$ had diabetes mellitus, 33\% arterial hypertension and $17 \%-$ coronary heart disease. The patients with mild to moderate, moderate to severe impairment of EF had the same tendencies to increase the percentage of those with concomitant diseases with deterioration of EF.

Table 5. Distribution according to EF and concomitant disease

\begin{tabular}{llll}
\hline Erectile function & Diabetes mellitus & Essential hypertension & Coronary heart disease \\
\hline Normal EF* & $0 / 28-0 \%$ & $6 / 28-21 \%$ & $3 / 28-11 \%$ \\
\hline Mild ED $\dagger$ & $1 / 12-8 \%$ & $4 / 12-33 \%$ & $2 / 12-17 \%$ \\
\hline Mild to moderate ED & $2 / 9-22 \%$ & $3 / 9-33 \%$ & $2 / 9-22 \%$ \\
\hline Moderate ED & $2 / 7-29 \%$ & $3 / 7-43 \%$ & $2 / 7-28 \%$ \\
\hline Severe ED & $3 / 8-38 \%$ & $4 / 8-50 \%$ & $3 / 8-37 \%$ \\
\hline
\end{tabular}

$* \mathrm{EF}-$ Erectile function, $\dagger \mathrm{ED}$ - Erectile dysfunction

\section{Discussion}

It is known that the preoperative $\mathrm{EF}$ is a significant predictor of the subsequent risk of ED following surgery [17]. The likelihood of satisfactory erections after surgery is extremely low in patients with severe ED as measured by IIEF [20, 21]. Patients with a higher preoperative IIEF are generally more motivated to achieve satisfactory erectile and sexual function after surgery [22]. Surgical technique and surgeons' experience also have a significant impact on the likelihood of ED after surgery [23-30]. Significant advances in the preservation of the sexual function of patients have been seen after the introduction of BNSRRP by P. Walsh [31-33]. This has led to increased patient expectations from the surgeon and stimulates the creation of different nomograms to predict postoperative outcomes in terms of sexual function. In the present study, 64 patients wished to maintain EF after BNSRRP. After an objective assessment of the preoperative sexual function of patients with clinically localized prostate cancer and candidates for the BNSRRP, we can conclude, that a large number of these patients $-56 \%$ had had impaired EF preoperatively. This shows that there is a significant discrepancy between the patient's personal assessment of the sexual function and that assessed via internationally validated questionnaires. The study also found that there was a clear correlation between the degree of ED and the accompanying diseases present. The more concomitant illnesses one patient has, the more impaired the EF is. Another important conclusion that we can make is that there is interdependence between the different domains of the IIEF. When the EF domain is deteriorating, there is a clear tendency for the other four domains to deteriorate.

\section{Conclusions}

Using the IIEF, we found that only $44 \%$ of all subjects selected for bilateral nerve sparing radical retropubic prostatectomy had preserved sexual function preoperatively and had a maximum score, according to the erection hardness score. This indicates that the majority of patients had impaired EF before surgery. This requires wider use of internationally validated questionnaires for a more accurate prognosis of postoperative sexual function. Last but not least, the results from these questionnaires may require a change in the operative technique and the treatment method used. To confirm our results, we need further studies to include a larger number of patients.

\section{References}

1. Siegel RL, Miller KD, Jemal A. Cancer statistics, 2016. CA Cancer J Clin. 2016;66:7-30.

2. Bill-AxelsonA, Holmberg L, Garmo H, Rider JR, Taari K, Busch C, et al. Radical prostatectomy or watchful waiting in early prostate cancer. $\mathrm{N}$ Engl J Med. 2014;370:932-42. 
3. Wallis CJD, Saskin R, Choo R, Herschorn S, Kodama RT, Satkunasivam R, et al. Surgery versus radiotherapy forclinically-localized prostate cancer: a systematic review and metaanalysis. Eur Urol. 2016;70(1):21-30.

4. Roach M. Radical prostatectomy $\mathrm{v}$ radiation: only a randomisedtrial can provide the answer. BMJ. 2014;348:g2266.

5. Schiavina R, Borghesi M, Dababneh H, Pultrone CV, Chessa F, Concetti S, et al. Survival, Continence and Potency (SCP) recovery after radical retropubic prostatectomy: a long-term combined evaluation of surgical outcomes. Eur J Surg Oncol. 2014;40(12):1716-23.

6. Mullins JK, Feng Z, Trock BJ, Epstein JI, Walsh PC, Loeb S. The impact of anatomical radical retropubic prostatectomy on cancer control: the 30-year anniversary. J Urol. 2012;188(6):221924.

7. Boorjian SA, Eastham JA, Graefen M, Guillonneau B, Karnes RJ, Moul JW, et al. A critical analysis of the long-term impact of radical prostatectomy on cancer control and function outcomes. Eur Urol. 2012;61(4):66475 .

8. Georgiev M, Ormanov D, Dimitrov P, Vassilev V, Yanev K, Simeonov P, et al. Comparison of anastomotic stricture rate after RRP between standard technique and Velthoven's running suture. Eur Urol. Suppl. 2010;9(6):560.

9. Salonia A, Burnett AL, Graefen M, Hatzimouratidis K, Montorsi F, Mulhall JP, et al. Prevention and management of postprostatectomy sexual dysfunctions. Part 1: choosing the right patient at the right time for the right surgery. Eur Urol. 2012;62(2):261-72.

10. Moskovic DJ, Miles BJ, Lipshultz LI, Khera M. Emerging concepts in erectile preservation following radical prostatectomy: a guide for clinicians. Int J Impot Res. 2011;23(5):181-92.

11. Merrill RM, Sloan A. Risk-adjusted incidence rates for prostate cancer in the United States. Prostate. 2012;72(2):181-5.

12. Sidana A, Hernandez DJ, Feng Z, Partin AW, Trock BJ, Saha S, et al. Treatment decisionmaking for localized prostate cancer: what younger men choose and why. Prostate. 2012;72(1):58-64.

13. Gandaglia G, Suardi N, Gallina A, Zaffuto E, Cucchiara V, Vizziello D, et al. How to optimize patient selection for robot-assisted radical prostatectomy: functional outcome analyses from a tertiary referral center. $\mathrm{J}$ Endourol. 2014;28(7):792-80.

14. Abdollah F, Sun M, Suardi N, Gallina A, Bianchi M, Tutolo $M$, et al. Prediction of functional outcomes after nerve-sparing radical prostatectomy: results of conditional survival analyses. Eur Urol. 2012;62(1):42-52.

15. Briganti A, Di Trapani E, Abdollah F, Gallina A, Suardi N, Capitanio U, et al. Choosing the best candidates for penile rehabilitation after bilateral nerve-sparing radical prostatectomy. J Sex Med. 2012;9(2):608-17.

16. Briganti A, Gallina A, SuardiN, Capitanio U, Tutolo M, Bianchi M, et al. Predicting erectile function recovery after bilateral nerve sparing radical prostatectomy: a proposal of a novel preoperative risk stratification. J Sex Med. 2010;7(7):2521-31.

17. Briganti A, Capitanio U, Chun FK, Karakiewicz PI, Salonia A, Bianchi M, et al. Prediction of sexual function after radical prostatectomy. Cancer. 2009;115(13):3150-9.

18. Gallina A, Ferrari M, Suardi N, Capitanio U, Abdollah F, Tutolo M, et al. Erectile function outcome after bilateral nerve sparing radical prostatectomy: which patients may be left untreated? J Sex Med. 2012;9(3):903-8.

19. Teloken PE, Nelson CJ, Karellas M, Stasi J, Eastham J, Scardino PT, et al. Defining the impact of vascular risk factors on erectile function recovery after radical prostatectomy. BJU Int. 2013;111(4):653-7.

20. Gacci M, Carini M, Simonato A, Imbimbo C, Gontero P, Briganti A, et al. Factors predicting continence recovery 1 month after radical prostatectomy: results of a multicenter survey. Int J Urol. 2011;18(10):700-8.

21. Harris CR, Punnen S, Carroll PR. Men with low preoperative sexual function may benefit from nerve sparing radical prostatectomy. J Urol. 2013;190(3):981-6.

22. Gandaglia G, Gallina A, Suardi N, Abdollah F, Passoni N, Bianchi M, et al. Preoperative erectile function is the only predictor of the use of a high number of phosphodiesterase type-5 inhibitors after bilateral nerve-sparing radical prostatectomy. Int J Impot Res. 2014;26(6):2014.

23. Gandaglia G, Suardi N, Gallina A, Abdollah F, Capitanio U, Salonia A, et al. Extended pelvic lymph node dissection does not affect erectile function recovery in patients treated with bilateral nerve-sparing radical prostatectomy. J Sex Med. 2012;9(8):2187-94.

24. Walsh PC, Donker PJ. Impotence following radical prostatectomy: insight into etiology and prevention. J Urol. 1982;128:492-7.

25. Walsh PC. The discovery of the cavernous nerves and development of nerve sparing radical retropubic prostatectomy. $\mathrm{J}$ Urol. 2007;177(5):1632-5. 
26. Ficarra V, Novara G, Ahlering TE, Costello A, Eastham JA, Graefen M, et al. Systematic review and meta-analysis of studies reporting potency rates after robot-assisted radical prostatectomy. Eur Urol. 2012;62(3):418-30.

27. Schatloff O, Chauhan S, Sivaraman A, Kameh D, Palmer KJ, Patel VR. Anatomic grading of nerve sparing during robot-assisted radical prostatectomy. Eur Urol. 2012;61(4):796-802.

28. Alemozaffar M, Duclos A, Hevelone ND, Lipsitz SR, Borza T, Yu HY, et al. Technical refinement and learning curve for attenuating neurapraxia during robotic-assisted radical prostatectomy to improve sexual function. Eur Urol. 2012;61(6):1222-8.

29. Graefen M, Beyer B, Schlomm T. Outcome of radical prostatectomy: is it the approach or the surgical expertise? Eur Urol. 2014;66(3):457-8.
30. Dimitrov P, Panchev P, Simeonov P, Vasilev V, Georgiev M, Yanev K. Prostate carcinoma staging and possibilities for operative treatment. Medical science. 2008;2:51-5.

31. Walsh PC. Radical prostatectomy for localized prostate cancer provides durable cancer control with excellent quality of life: a structured debate. J Urol. 2000;163(6):1802-7.

32. Kolev N, Atanasov J, Dunev V, Stoykov B, Kotsev R, Vanov A, et al. Open Retropubic and Robot-Assisted Radical Prostatectomy in Prostate Carcinoma: Advantages of Methods. Journal of Biomedical and Clinical Research. 2016;9(2):145-9.

33. Hinev A, Hadjiev V, Kolev N. Validation of preoperative nomograms predicting lymph node involvement in prostate cancer: a Bi-institutional study. Eur Urol. 2011;60(6):1310-1. 